DOI: http://dx.doi.org/10.22198/rys.2018.72.a784

Artículos

\title{
Metodología para la clasificación de industrias culturales/creativas en una ciudad media: Culiacán, Sinaloa, México
}

\author{
A methodology for classifying cultural/creative \\ industries in a medium-sized city: \\ Culiacan, Sinaloa, Mexico
}

\section{Paola Marbella Canizalez Ramírez* Ezequiel Avilés Ochoa**}

Resumen: este análisis está encaminado a esquematizar una propuesta metodológica para clasificar las industrias culturales/creativas en Culiacán, y determinar su contribución a la dinámica productiva, a partir del Sistema de Clasificación Industrial de América del Norte, de 2013, y la Classification Guide for the Canadian Framework for Culture Statistics, de 2011. Ante la limitada construcción empírica sobre el tema en México, el propósito es realizar una clasificación útil para unificar las ocupaciones involucradas en la creación, producción y distribución, a través de dominios para concretar un ordenamiento que precise la operatividad de nueve industrias en esta ciudad, a partir del cotejo estadístico por

\footnotetext{
* Autora para correspondencia. Doctorado en estudios regionales con énfasis en América del Norte, Universidad Autónoma de Sinaloa. Josefa Ortiz de Domínguez s/n, Ciudad Universitaria, C.P. 80040. Culiacán, Sinaloa, México. Correo electrónico: paola.canizalez@gmail.com

** Profesor-investigador de la Universidad de Occidente, unidad Culiacán. Boulevard Lola Beltrán s/n, edificio H, colonia 4 de Marzo, C. P. 80020. Culiacán, Sinaloa, México. Teléfono: (667) 759 1300, extensión 2302.Correo electrónico: ezequiel.aviles@udo.mx
} 
ramas económicas de los sectores secundario y terciario. Se concluye que el volumen y el crecimiento de actividades, firmas y empleo detectados delimitan las industrias culturales/creativas, aptas para promover la capacidad del sistema de producción en un cluster económico local. La clasificación es flexible y no exceptúa omisiones, más bien puede resultar concebible en otras ciudades.

Palabras clave: industrias culturales/creativas; economía cultural; economía regional; cluster; Culiacán.

Abstract: this analysis is aimed at schematizing a methodological proposal for classifying cultural/creative industries in $\mathrm{Cu}$ liacan, and determining their contribution to production dynamics, based on the North American Industry Classification System, 2013, and the Classification Guide for the Canadian Framework for Culture Statistics, 2011. In view of the limited empirical construction on the subject in Mexico, the purpose is to carry out a classification useful for unifying the occupations involved in creation, production and distribution through domains in order to implement a regulation that specifies the operability of nine industries in this city, based on the statistical comparison by economic branches of the secondary and tertiary sectors. It follows that the volume and growth of detected activities, firms and employment delimit the cultural/creative industries which are apt for promoting the production system's capacity in a local economic cluster. The classification is flexible and does not exclude omissions; it rather can be conceivable in other cities.

Keywords: cultural/creative industries; cultural economy; regional economy; cluster; Culiacan.

Recibido el 16 de junio de 2016. Aceptado el 30 de mayo de 2017. 


\section{Introducción}

El surgimiento de prácticas centradas en la creatividad, el capital humano y las innovaciones tecnológicas propició la redefinición del funcionamiento del sistema económico, y la construcción de un paradigma fundamentado en la difusión del conocimiento. La economía cultural emerge en esta disrupción, como condición de los cambios en el orden de producción del modelo tradicional, la aceleración de la demanda, el consumo y la comercialización de bienes y servicios, que incorporan valor simbólico, artístico, identidad individual, connotación intelectual y alta tecnología.

Entre 1970 y 1980, esta economía alcanzó prominencia en el contexto del declive industrial y la especulación financiera; el capital empresarial innovador se inclinó por la elaboración e inversión en productos creativos, que no se pueden reproducir fácilmente en cualquier sitio (Zukin 1995, 8). En efecto, la cultura adquirió un papel fundamental en la economía moderna en los últimos 20 años (Lorenzini 2011, 1441), partícipe del proceso del cambio económico, contextualiza el crecimiento en la era moderna, por la expansión del “conocimiento útil” (Mokyr 2017, 4).

El resultado de la concurrencia de las fuerzas extraeconómicas en mercados imperfectos es la agrupación de las industrias culturales, una rama de actividad no tradicional (Scott 2008, 64), donde la producción y la comercialización se intersectan con las dimensiones social y política de las personas, y con la subjetividad cognitiva de una economía articulada por sectores especializados. Estas industrias se reconocen por la aglomeración de manufacturas y servicios con alta especialización organizacional, innovación tecnológica, transacciones intensivas interfirmas y diseño especializado (Scott 2010). La inserción de la creatividad, como insumo diferenciado en la función de producción territorial, las sitúa como un epítome del cambio estructural. En las regiones donde surgen y se expanden, se despliegan las actividades con rendimientos crecientes, elasticidad ingreso positiva y un ingreso per cápita alto.

En contraparte, en las economías con una estructura productiva rígida se manifiesta un viraje hacia ciclos volátiles y tendencias esta- 
cionarias. Tal rasgo motiva, entre los actores locales, la exigencia de la construcción endógena de competencias territoriales que atenúe las fluctuaciones. La estrategia está centrada en el impulso de manufactura de productos no estandarizados en tecnología, servicios financieros y personales; asimismo, en la irrupción de industrias culturales, dispuestas en medios de comunicación y artesanías de producción intensiva (Scott 2014, 569).

En las industrias culturales/creativas se observa una propensión significativa a la aglomeración en grandes urbes, con formas articuladas de interacción social, relativas a la reproducción del aprendizaje, la creatividad y la innovación. Estas industrias se convierten en herramientas de regeneración urbana y estímulo del crecimiento económico; también, las ciudades se trasforman en espacios creativos, mediante estrategias que combinan la edificación de infraestructura junto con la alineación de cuarteles y clusters especializados (Stevens $2015,1)$. No obstante, la discusión acerca de su contribución a la dinámica productiva local permanece más en el ámbito teórico que en el empírico. El vacío es el resultado de la carencia de un sistema de clasificación, aceptado por la comunidad científica, que permita generar una base estadística comparable entre países, regiones o localidades (Throsby 2008a).

En la búsqueda de sistemas existe una confrontación, pues como lo señala Pratt, el análisis de la cultura yuxtapone categorías, y el enfoque disciplinario de economía y cultura provoca estudios parciales en temáticas variadas, lo cual se traduce en dificultades de repercusión, delimitación y definición $(1997,2)$.

Para Hesmondhalgh (2002), el término industrias culturales es controvertido, los problemas para definirlo derivan de la dificultad de precisar el significado de cultura (por no mencionar el de industria). O'Connor, por su parte, señala que la tensión entre cultura y economía se encuentra en el centro de una terminología evolutiva: desde la industria cultural hasta las creativas $(2007,7)$.

Galloway y Dunlop (2007) advierten que debido a la confusión terminológica que rodea al término cultura, las deliberaciones y los modelos analíticos han fracasado en considerar de manera adecuada las diferencias entre las actividades culturales y las creativas. Markusen et al. $(2008,24)$ subrayan que los términos creativo y cultural se 
utilizan sin tener una definición clara. Para Kong, aunque es posible someter el discurso teórico a variantes como industria cultural, industrias culturales o industrias creativas, estas últimas resultan contenciosas respecto a su categorización, definición e implementación y, en consecuencia, se dificulta la medición de su aporte al crecimiento $(2014,596) \mathrm{I}$ draw attention to the complexities and confusions in the shift in discourse and praxis from \u201cculture industry $\backslash$ u201d to \u201ccultural industries $\backslash u 201 d$ and then $\backslash u 201$ ccreative industries. \u201d I examine how this \u201ccreative turn \u201d is fraught with challenges, highlighting seven issues in particular: (i. "A pesar de un considerable cuerpo de trabajo, no se esclarecen aún las características que identifican a las industrias creativas" (Peltoniemi 2015, 41).

Es complicado elaborar una distinción determinante entre industrias culturales y creativas que, cada vez más, dejan una influencia clara sobre perspectivas de integración en estrategias de desarrollo locales y regionales; los dos enfoques no son mutuamente excluyentes, sino útiles para fines diferentes (O'Connor 2011, 25). El interrogante que se desprende de estas consideraciones es ¿cómo determinar la contribución de las industrias culturales en la estructura y dinámica productiva de un territorio urbano delimitado? El objetivo principal de este trabajo es esquematizar una propuesta metodológica que permita clasificar la industria cultural en una ciudad media, a partir del Sistema de Clasificación Industrial de América del Norte (SCIAN) México (Instituto Nacional de Estadística y Geografía, INEGI 2013) y la Classification Guide for the Canadian Framework for Culture Statistics (CGCFCS) (Canadian Framework for Culture Statistics 2011), marco referencial que armoniza definiciones o criterios diferentes en la producción de estadísticas culturales; la ciudad en estudio es Culiacán, Sinaloa, México. Asimismo, se ofrecen respuestas a interrogantes que caracterizan la economía cultural: ¿cómo se clasifica una industria cultural?, y ¿cuál es el efecto de su dinámica creativa en el espacio de una ciudad?

El esfuerzo metodológico se concreta en un esquema que facilita el cotejo estadístico de ramas económicas de los sectores secundario y terciario de una ciudad media, y descarta actividades no compatibles con la conceptualización de industrias culturales. La contribución de 
esta investigación permite armar la estructura de firmas, estimar el número de empleados, cuantificar tasas de crecimiento y justificar la presencia, las características y la variedad de las industrias culturales.

\section{Prefacio a un nuevo orden:}

la economía cultural y sus manifestaciones

En la teoría neoclásica del crecimiento se observa una corriente que sitúa a los insumos creativos, al aprendizaje y a la innovación, como variables explicativas centrales. En países desarrollados se despliega una economía cultural intensa, cuyos sectores tutelados por la manufactura de tecnología, los modelos de negocios, los servicios financieros, el diseño de moda y las industrias culturales aceleran procesos dispuestos a fragmentar los procedimientos de la mano de obra y la desestandarización. Asimismo, se intensifica la competencia de bienes y servicios con alto contenido cognitivo-cultural y rasgos cuasi monopólicos, que los hace sustitutos imperfectos unos de otros (Scott 2008, 65-66). Surge así una nueva división del trabajo, con una fuerza laboral de elite concentrada en aprovechar recursos intelectuales y creativos.

La creatividad no representa una cualidad etérea y externa, sino una reflexión material arraigada en los desafíos y las oportunidades que enfrentan los trabajadores de la industria. Tiene un carácter social en procesos de efusión colectiva de ideas, mensajes y símbolos que, en entornos propicios, son considerados como uno más de los factores de la producción. Estudios recientes sobre el significado de creatividad, economía y espacio integran un cuerpo teórico que razona sobre conceptos como ciudad creativa (Landry y Bianchini 1995); industrias creativas e industrias culturales (Scott 2001); clase creativa (Florida 2003); economía creativa, economía del conocimiento y economía cultural (Throsby 2001); economía cognitivo-cultural (Scott 2008); cuarteles culturales (Montgomery 2003); cluster creativo (Evans 2009); cluster cultural (Mommaas 2004) y economía urbana (Amin y Thrift 2007).

La expresión más tangible de la economía cultural se manifiesta en un segmento distintivo: las industrias culturales. Actividades que 
se ocupan principalmente de bienes simbólicos, cuyo valor económico primario se deriva de su valor cultural (O'Connor 2000, 19). Hesmondhalgh asume que "más que otros tipos de producción, las industrias culturales se involucran en la elaboración y difusión de productos (textos) que tienen una influencia en nuestra comprensión del mundo" $(2002,3)$. Estas industrias representan un ejemplo práctico de las relaciones híbridas y complejas entre producción, consumo y entre lo material y lo simbólico (Pratt 2008). Se identifican con el proceso de producción, consumo e intercambio de bienes y servicios culturales, que requieren de la creatividad humana (Throsby 2008b). Constituyen un ensamble de sectores que ofrecen servicios especializados y productos manufacturados, por medio de los cuales el consumidor construye formas distintivas de individualidad, autoafirmación y comportamiento social (Scott 2008). La economía cultural se extiende en el espacio y su expresión más particular se identifica por un segmento organizado de las industrias culturales.

\section{Industrias culturales, ciudad y formas espaciales de la creatividad}

En el estudio de la creatividad y su repercusión en la dinámica productiva de las ciudades destaca el rol de las industrias culturales, como un sector involucrado en procesos de producción especializados, y sustentados en la innovación y la organización social. Entre los acercamientos teórico-empíricos que explican este fenómeno sobresalen las aportaciones de Scott $(2001,1997)$; Pratt (2004; 1997); Mommaas (2004); Markusen (2006); Hutton (2006) y Lazzeretti et al. (2009; 2008). En los espacios urbanos se manifiesta una mezcla compleja de regímenes de producción industrial, como los vestigios de la fábrica prefordista e industrias residuales fordistas, así como formaciones más recientes de producción y mano de obra especializada posfordista y neoartesanal (Hutton 2006, 1819).

En la articulación de los sectores de industrias culturales/creativas, los productores y firmas son proclives a concentrarse en razón de la naturaleza de sus productos y servicios culturales -creativos, idiosincráticos, simbólicos e ideológicos-, que demandan innovación cons- 
tante para su producción. De esta manera, la clusterización creativa se fundamenta en variantes de los factores de aglomeración marshalliana tradicionales, lo que Lorenzen y Frederiksen (2008) señalan como el aprovechamiento de los efectos de rendimientos crecientes por la colocalización y las economías de urbanización.

La creatividad es la "capacidad creativa de la cultura, un recurso para la innovación, porque tiene el poder de revitalizar ciudades, distritos, sectores, profesiones, bienes a través de la generación de nuevas ideas, fertilización cruzada y serendipia” (Lazzeretti 2009, 282). Entonces, "la producción cultural está estrictamente ligada a la dimensión territorial” (Lorenzini 2011, 1442), la aglomeración espacial de industrias culturales/creativas apunta hacia el significado de la creatividad, como un factor más de producción y construcción del entramado socioeconómico en el ambiente de la urbe.

La cultura es el eje sobre el cual se articula el crecimiento económico de las ciudades (Guerrero y Navarro 2012, 72). En este sentido, las metrópolis despliegan este tipo de economía, con una estructura de relaciones y prácticas creativas. Mckenzie y Hutton (2015) afirman que la cultura, en sus formas diversas y complejas, contribuye a la expansión de ciudades creativas, y abarca producción, consumo y espectáculo. Entre las nociones que examinan la producción cultural creativa y sus formas espaciales -cluster/distrito/cuartel/escena- destaca la de Mommaas (2009), quien define al cluster creativo-cultural en tres dimensiones: a) calidad y rol cultural; b) escala y sustancia de relaciones de proximidad y distancia en la que operan y c) características económicas y políticas. Por su parte, Van Heur (2009) distingue el cluster creativo como un fenómeno que describe relaciones nuevas entre producción y localización urbana; sin embargo, asume que no se caracteriza por concentraciones territoriales de creatividad, sino como nodos que descansan en la proximidad espacial.

Lazzeretti et al. (2008) examinaron empíricamente la clusterización de industrias creativas a partir de un análisis comparativo entre Italia y España. Explican que los determinantes de aglomeración incluyen la agrupación territorial de los sistemas locales de producción, el empleo y la especialización entre dos tipos de industrias creativas: las culturales tradicionales (edición, arquitectura, música, filme, video y artes escénicas) y las no tradicionales (relacionadas con la tec- 
nología, como research \& development -R\&D-, software y los servicios de cómputo y la publicidad) $(2008,8)$.

En 2009, Lazzeretti et al., propusieron un modelo de estimación correlacional, para ello midieron el empleo creativo en el sistema de producción local y la incidencia de variables, como el patrimonio histórico y cultural, las economías de localización y las de urbanización, la variedad relacionada, la tecnología y la tolerancia. Concluyeron que la intensidad y especificidades de estas variables incidían en el surgimiento de patrones variados de clusterización de industrias culturales. Para Scott (2010), las firmas se aglomeran en clusters especializados densos o distritos industriales con redes transaccionales, que los sostienen como entidades geográficas. Al mismo tiempo, un sistema urbano desarrollado juega un rol protagónico en el sostenimiento de unidades de creatividad individual, a través de formas de reproducción social.

El carácter urbano del fenómeno de clusterización de actividades creativas-culturales se fusiona a la estructura de la ciudad y su entramado social. La producción se dispersa en redes con firmas numerosas y variadas, donde los encadenamientos fuertes advierten y dan pauta a las aglomeraciones compactas -clusters creativos de industrias culturales-, que tienden a la desintegración vertical y horizontal. En el cluster, las firmas deciden la escala de producción, pero la concentración del sistema involucra redes de transacciones intensivas entre las pequeñas.

Los determinantes de costos de transacción son multidimensionales (distancia, modos y grado de interacción, escala y contenido sustancial de vínculos y carácter de las interdependencias). Su interrelación funcional origina la circulación de ideas y estimula la creatividad. Las firmas, en especial las que le dan importancia al diseño imaginativo del producto, ordenan su operación interna en el trabajo en equipo por proyectos, donde empleados permanentes, personal de medio tiempo y especialistas independientes se combinan para unir experiencia y talento.

La red del cluster creativo genera etapas expansivas de economías externas al fragmentar y profundizar la división del trabajo; la aglomeración se torna más compleja. En otras palabras, se genera una causación circular acumulativa que al final sostiene el crecimiento, 
un ingrediente adicional es el territorio en sí mismo. No sólo como una colección de capacidades industriales, sino como una reserva de tradiciones, memorias e imágenes que actúan como fuentes de inspiración para diseñadores y trabajadores manuales, plasmadas en los productos finales (Scott 2006, 74-75).

El desarrollo de este tipo de aglomeraciones plantea un interrogante: ¿se puede medir y advertir el surgimiento de un cluster de industrias culturales con potencial creativo? Para plantear hipótesis que expliquen esta pregunta es necesario clasificar el quehacer creativo del territorio objeto de análisis, a partir de esquematizar las actividades productivas de los sectores secundario y terciario, cuyo corte empírico y medición aportan una valoración estadística significativa.

\section{Una metodología para la clasificación de industrias culturales}

Las empresas productoras de bienes y servicios culturales, cuya manufactura intangible es tan real como la tradicional, reúnen una gran cantidad de recursos intelectuales y creativos. La parte medular del proceso productivo se revela en un elemento expresivo o simbólico: la creatividad humana y la innovación individual y grupal (United Nations Development Programme 2013, 17-22). En 2010, el comercio mundial de bienes y servicios creativos fue de 559.5 billones de dólares, y el año siguiente de 624 billones. En el lapso 2002-2011, el intercambio global se duplicó, la tasa de crecimiento promedio anual fue de 8.8 por ciento; las exportaciones se expandieron a 12 , y al final del periodo representaron 227 billones de dólares, equivalente a 50 por ciento del total (United Nation Conference on Trade and Development 2013).

El liderazgo de las industrias culturales favorece la expansión de regiones orientadas a la especialización de productos y servicios, y estimula patrones nuevos de competencia y formas de organización. Sin embargo, en su valoración existen dificultades conceptuales y metodológicas; algunas se refieren a qué se debe considerar como una industria cultural, situación que genera ambigüedades sobre su defi- 
nición y delimitación, y otras discuten sobre cuántas existen y dónde localizarlas (Guerrero y Navarro 2012, 73). Todo ello se traduce en problemas de estructura, indicadores, categorías y operatividad y, en general, dificultades para crear sistemas de clasificación, que posibiliten analizar la importancia y contribución de las industrias culturales en la dinámica económica local.

El debate en torno al concepto es fragmentado y complejo; comenzó en 1947, a partir de la crítica de Horkheimer y Adorno (Adorno 1991) sobre la masificación de la cultura. Después fue objeto de interés político y académico (O’Connor 2011, 27). En 1997, el cambio de una política, delineada por el Creative Industries Taskforce del Reino Unido, motivó que el discurso girara hacia una noción novedosa, pero paralela: las industrias creativas.

En la década de 1990 el análisis se extendió al escenario empírico. Entre las contribuciones relevantes destaca la de Pratt (1997), quien subrayó la necesidad de estudios sobre la naturaleza y la organización de industrias culturales en lugares particulares, a fin de entender la red de relaciones de producción, mercados de trabajo y entorno socialcultural. Por su parte, Flew (2002) cuestionó el uso del concepto, subrayó que si a las industrias se les definiera como los sectores involucrados en la producción de bienes y servicios simbólicos sería insostenible excluir toda la productividad industrial que tuviera una dimensión simbólica.

Hesmondhalgh (2007) reconoció que al concepto de industrias culturales se le sumó otra interpretación, la de las industrias creativas. La dificultad para definir ambos términos se debe superar en el análisis concerniente al dominio de cómo los bienes culturales se producen y extienden en las economías y sociedades modernas. Galloway y Dunlop juzgan que la mayoría de las definiciones se limitan a mezclar cinco criterios: creatividad, propiedad intelectual, significado simbólico, valor de uso y métodos de producción, lo que aumenta la confusión conceptual y reduce el análisis teórico en la formulación de modelos alternativos $(2007,19)$.

Existen tipologías para la categorización de los sectores creativos/ culturales, que varían en características y estructura, como el Creative industries mapping document, del Departamento de Cultura, Medios 
y Deporte del Reino Unido, de 1998; ${ }^{1}$ el modelo basado en derechos de autor adoptado por la Organización Mundial de la Propiedad Intelectual; los modelos derivados de una perspectiva de estudios culturales en los que estas industrias se consideran proveedores de textos simbólicos (Hesmondhalgh 2002), y el modelo desarrollado en el Instituto de Estadística de la Organización de Naciones Unidas para la Educación, la Ciencia y la Cultura (Throsby 2008b, 148).

Throsby (2008a) reconoce que las conceptualizaciones de industrias culturales conducen a la construcción de múltiples modelos del sector de producción cultural y, por lo tanto, a industrias diferentes comprendidas dentro de él. Throsby estructuró una categorización a partir de datos empíricos: literatura, música, artes escénicas, artes visuales, filme, museos-galerías-bibliotecas, fotografía, servicios del patrimonio, publicación y medios impresos, grabación de sonido, televisión y radio, videojuegos y juegos de computadora, publicidad, arquitectura, diseño y moda (2008b, 149).

Por otro lado, O'Connor (2011) encuentra que en un extremo hay intentos puramente empíricos por definir y delimitar el sector, por lo general en forma estadística, sobre todo para precisar y establecer su valor.Y también que el término responde a intereses que desean aprovechar su contenido y adaptarlos para lograr objetivos particulares.

En un aporte reciente, Kong favorece el término de industrias culturales, y propone clarificar el entendimiento de los sectores culturales y el trabajo creativo involucrado, al reconocer las diferencias de sectores a través de categorías, como el arte, los medios de comunicación y el diseño de productos, para así comprender los retos y evitar la confusión en el uso e interpretación de información estadística e instrumentos de política $(2014,604)$.

Lazzeretti et al. $(2015,9)$ presentaron un conjunto de industrias culturales y creativas que consideraron como el más utilizado en su campo de estudio, a partir del orden reciente del Departamento de Cultura, Medios y Deporte de Reino Unido (2013): publicidad, arquitectura, artes y entretenimiento, programación informática, actividades del diseño, filme-video-televisión, fotografía, actividades de

1 https://www.gov.uk/government/publications/creative-industries-mapping-documents-1998 
programación y difusión (TV y radio), edición, grabación de sonido y música. La configuración de los sistemas de clasificación puede superar las dificultades de conceptualización, si éstos se sujetan a las características específicas de las industrias en el sitio que se analiza (fuerza laboral, unidades económicas, rama de actividad). Sin embargo, la especulación acerca de la significancia y cuantía de su repercusión en la economía local aumenta los criterios para avalar datos de medición. Guerrero y Navarro $(2012,79)$ subrayan que entre los problemas principales que enfrenta el estudio de las industrias culturales son las fuentes para identificarlas y localizarlas, a partir de criterios del producto agregado y la fase del proceso de producción. Esto se acentúa más en el ámbito de las ciudades, donde es conveniente evaluar cada sector individual, para no confundir datos, estadísticas y dispersión de conceptos.

\section{Caso de estudio: Culiacán, Sinaloa, México}

La capital del estado de Sinaloa, Culiacán, es una ciudad de tamaño medio, connotación socioeconómica que la identifica como un centro urbano (con más de 15 mil habitantes), no conurbado ni comprendido en las grandes zonas metropolitanas (Consejo Nacional de Población 2012,13). Su extensión geográfica es de 4758 km² y está ubicada en el noroeste de México; es el núcleo urbano de un valle agrícola extenso localizado entre la Sierra Madre Occidental y el mar de Cortés, tiene 905265 habitantes, que representan 32 por ciento del total estatal (INEGI 2016); su densidad poblacional es de 166.8 personas por $\mathrm{km}^{2}$; el ingreso per cápita anual es de 6298 dólares, y aporta 48.4 por ciento del producto interno bruto del estado (INEGI 2014b).

El municipio es líder estatal en producción de maíz y en horticultura de exportación (tomate, pepino, chile, berenjena y calabaza). La aglomeración urbana le otorga ventajas para la localización industrial; dispone de infraestructura de servicios educativos, salud y administración pública, además mantiene su hegemonía política sobre otros centros urbanos; más de 60 por ciento de la población económicamente activa trabaja en el sector servicios. 
Para definir una clasificación susceptible de aplicación empírica, la metodología se diseña a partir del SCIAN 2013, mediante la desagregación selectiva de los sectores secundario y terciario, que permite la clasificación de industrias potencialmente creativas. El objetivo de este artículo es aportar un esquema estadístico para estudios comparados de ciudades similares, cuya materia de análisis sea las industrias culturales y su contribución a la dinámica productiva local y regional.

\section{Caracterización de un cluster de industrias culturales /creativas en Culiacán}

Si bien en la literatura no existe una delimitación precisa de las industrias culturales/creativas y sus márgenes conceptuales, dimensionales o geográficos, es posible diseñar una propuesta operativa y asequible para Culiacán. La evidencia empírica advierte la presencia de un sistema de producción sujeto de esta clasificación. Para examinar tal presunción, se formula una caracterización estadística para cotejar 13 sectores manufactureros y de servicios (véase Figura 1).

De 1998 a 2008 hubo un incremento de 7838 unidades económicas, de las cuales el sector servicios registró un aumento de 3 733, que significó 51.3 por ciento y una aportación de 41 al total de establecimientos de la ciudad, en 2008. La manufactura agregó 906 unidades, que representaron 10.2 por ciento del total en 2008. En dicho decenio ocurrió un cambio en la estructura económica de la ciudad, que favoreció al sector servicios, pues tuvo una variación de 63 por ciento en el personal ocupado, con una aportación de 33.6 al personal ocupado total de la ciudad en 2008, en tanto que la manufactura significó 12.16. El personal ocupado promedio en el sector servicios es de 5 personas por unidad económica, cifra que se utiliza en el presente análisis para estimar la participación del empleo en cada industria clasificada. Por otro lado, aunque la tendencia de gastos por consumo de bienes y servicios en el sector secundario es mayor al del terciario (véase Figura 2), entre 1998 y 2008 el sector servicios creció 3.8 veces y el de la manufactura 2.4. 
Figura 1. Unidades económicas y personal ocupado en los sectores manufacturero y de servicios. Culiacán, Sinaloa

\begin{tabular}{|c|c|c|c|c|}
\hline \multicolumn{5}{|c|}{$(1998,2003,2008)$} \\
\hline Indicador & Unidad de medida & 1998 & 2003 & 2008 \\
\hline Total de unidades económicas & Unidades económicas & 18755 & 21725 & 26593 \\
\hline $\begin{array}{c}\text { Unidades económicas. } \\
\text { Sector 31-33. Unidades } \\
\text { manufactureras }\end{array}$ & Unidades económicas & 1815 & 2014 & 2721 \\
\hline $\begin{array}{c}\text { Unidades económicas. Gran } \\
\text { sector } 51,53,54,55,56,61 \\
62,71,72 \text { y } 81 . \text { Servicios } \\
\text { privados no financieros }\end{array}$ & Unidades económicas & 7276 & 8759 & 11009 \\
\hline $\begin{array}{l}\text { Unidades económicas. } \\
\text { Sector 52. Servicios } \\
\text { financieros y seguros }\end{array}$ & Unidades económicas & 103 & 140 & 219 \\
\hline Personal ocupado total & Número de personas & 113379 & 136693 & 177099 \\
\hline $\begin{array}{l}\text { Personal ocupado total } \\
\text { por unidad económica }\end{array}$ & Número de personas & 6 & 6 & 7 \\
\hline $\begin{array}{c}\text { Personal ocupado promedio } \\
\text { por unidad económica. } \\
\text { Sector 31-33. Industrias } \\
\text { manufactureras }\end{array}$ & Número de personas & 8 & 8 & 8 \\
\hline $\begin{array}{l}\text { Personal ocupado promedio } \\
\text { por unidad económica. Gran } \\
\text { sector servicios } 51,53,54, \\
55,56,61,62,71,72 \text { y } 81 \\
\text { Servicios privados } \\
\text { no financieros }\end{array}$ & Número de personas & 5 & 5 & 5 \\
\hline $\begin{array}{l}\text { Personal ocupado promedio } \\
\text { por unidad económica. } \\
\text { Sector 52. Servicios } \\
\text { financieros y de seguros }\end{array}$ & Número de personas & 7 & 11 & 11 \\
\hline $\begin{array}{l}\text { Personal ocupado total. } \\
\text { Sector 31-33. } \\
\text { Industrias manufactureras }\end{array}$ & Número de personas & 14102 & 16384 & 21547 \\
\hline $\begin{array}{l}\text { Personal ocupado total. Gran } \\
\text { sector servicios } 51,53,54 \text {, } \\
55,56,61,62,71,72 \text { y } 81 . \\
\text { Servicios privados } \\
\text { no financieros }\end{array}$ & Número de personas & 36565 & 41281 & 59601 \\
\hline $\begin{array}{l}\text { Personal ocupado promedio } \\
\text { por unidad económica. } \\
\text { Sector 52. Servicios } \\
\text { financieros y de seguros }\end{array}$ & Número de personas & 761 & 1534 & 2341 \\
\hline
\end{tabular}

Fuente: elaboración propia, con información del INEGI (2014a). 
Figura 2. Gastos por consumo, ingreso y valor censal de los sectores manufactureros y de servicios en Culiacán (miles de pesos)

\begin{tabular}{|c|c|c|c|}
\hline Indicador & 1998 & 2003 & 2008 \\
\hline $\begin{array}{c}\text { Total gastos por consumo } \\
\text { de bienes y servicios }\end{array}$ & 30329720 & 46575615 & 90655148 \\
\hline $\begin{array}{c}\text { Total gastos por consumo } \\
\text { de bienes y servicios. Sector 31-33. } \\
\text { Industrias manufactureras }\end{array}$ & 2962934 & 5128712 & 10235094 \\
\hline $\begin{array}{c}\text { Total gastos por consumo } \\
\text { de bienes y servicios. Gran sector 51, } \\
\text { 53, 54, 55, 56, 61, 62, 71, 72 y 81. } \\
\text { Servicios privados no financieros }\end{array}$ & 1485663 & 2891244 & 7209411 \\
\hline $\begin{array}{c}\text { Total gastos por consumo } \\
\text { de bienes y servicios. Sector 52. } \\
\text { Servicios financieros y de seguros }\end{array}$ & 269639 & 1823148 & 3588301 \\
\hline $\begin{array}{c}\text { Total ingresos por suministro } \\
\text { de bienes y servicios }\end{array}$ & 38385617 & 61168789 & 114072159 \\
\hline $\begin{array}{c}\text { Total ingresos por suministro } \\
\text { de bienes y servicios. Sector 31-33. } \\
\text { Industrias manufactureras }\end{array}$ & 4093038 & 7163149 & 14081944 \\
\hline $\begin{array}{c}\text { Total ingresos por suministro } \\
\text { de bienes y servicios. Gran sector 51, } \\
53 \text { 54, 55, 56, 61, 62, 71, 72 y 81. } \\
\text { Servicios privados no financieros }\end{array}$ & 2764819 & 6485097 & 14473085 \\
\hline $\begin{array}{c}\text { Total ingresos por suministro } \\
\text { de bienes y servicios. Sector 52. } \\
\text { Servicios financieros y de seguros }\end{array}$ & 344720 & 2020388 & 2949956 \\
\hline $\begin{array}{c}\text { Valor agregado } \\
\text { censal bruto. Sector 31-33. } \\
\text { Industrias manufactureras }\end{array}$ & 1156563 & 2117170 & 3886366 \\
\hline $\begin{array}{c}\text { Valor agregado censal bruto. } \\
\text { Gran sector 51, 53, 54, 55, }\end{array}$ & 1292815 & 3680544 & 6645434 \\
$\begin{array}{c}56,61,62,71,72 \text { y 81. } \\
\text { Servicios privados no financieros }\end{array}$ & & 272258 & 135679 \\
\hline $\begin{array}{c}\text { Valor agregado censal bruto. Sector 52. } \\
\text { Servicios financieros y de seguros }\end{array}$ & & & \\
\hline
\end{tabular}

Fuente: elaboración propia, con información del INEGI (2014a).

En el periodo 1998-2008, el ingreso total por suministro de bienes y servicios se triplicó, con una variación de 197.1 por ciento; los ingresos por bienes y servicios del sector servicios crecieron más de 
cuatro veces en el mismo periodo, en 2008 significó 12.6 por ciento del total en este apartado, la manufactura aportó 12.3. El valor agregado censal bruto tuvo el incremento más alto en los servicios, pues de 1998 a 2008 aumentó casi cinco veces el valor añadido a bienes y servicios (499 por ciento), la manufactura creció 1.5 veces.

La evidencia permite inferir la presencia de un cluster emergente. Al desagregar el número de unidades económicas y el personal ocupado por sectores, se observa la presencia de capital humano y atributos espaciales y locacionales en la estructura productiva local. Se distingue un grupo de actividades industriales, que conforman prácticas diferenciadas espacialmente, que moldean la interempresarialidad en formas variadas. Lo que no es tan claro es la eficacia de las interrelaciones.

Si bien en el caso en estudio hay actividades especializadas, no parecen amalgamadas o interdependientes, entonces, se trata de empresas con dinámicas localizadas en el mismo espacio geográfico, delimitadas como un cluster económico funcional. En este contexto, la propuesta de clasificación se puede emplear para ordenar la estructura productiva de las industrias culturales/creativas, y sistematizar la formación de aglomeraciones distintivas en la geografía de una ciudad media.

\section{Marco conceptual}

Para evitar incongruencias en el trazo estadístico, antes del ejercicio de clasificación se precisaron lineamientos de la CGCFCS y del SCIAN; según este último, los productos informativos y culturales, así como los procesos involucrados en su fabricación y distribución tienen estas características: a) la información o el producto no poseen necesariamente cualidades tangibles, ni están asociados con una forma en particular; b) la entrega no requiere del contacto directo entre proveedor y consumidor; c) el valor no radica en las cualidades tangibles del bien o servicio, sino en su contenido informativo, educativo, cultural o de entretenimiento; d) pueden reproducirse con facilidad; e) la intangibilidad de la posesión hace que los procesos involucrados 
en su fabricación y distribución sean distintos a los empleados en los bienes y servicios tradicionales. Sólo quienes poseen los derechos están autorizados para reproducirlos, alterarlos, mejorarlos y asignarlos y f) los distribuidores pueden agregar valor a los bienes que comercializan (INEGI 2013).

Por su parte, en la CGCFCS, "la cultura se define como la actividad artística creativa y los bienes y servicios producidos, por ella y la preservación del patrimonio". Un bien y servicio cultural debe cumplir con uno de los criterios siguientes: a) tener el potencial de ser protegido por derechos de propiedad intelectual; b) apoyar la creación, la producción, la diseminación o la preservación de los productos culturales; c) agregar o alterar el contenido de un producto cultural; d) preservar, exhibir o interpretar la herencia humana o natural; e) proveer entrenamiento o servicios educativos dirigidos a individuos que crean, producen o preservan productos culturales o f) gobernar, financiar o apoyar directamente la creación, la producción o la diseminación de la cultura (Canadian Framework for Culture Statistics 2011, 23).

En la elaboración de los productos culturales pueden participar tanto los sectores de manufactura tradicional, como los de servicios, que involucran transacciones personalizadas, o que trasmiten información; también surgen en forma híbrida (Scott 1997, 323). Son sujetos del diseño de arquetipos, elementos de contenido simbólico y estilos que se combinan sin cesar, pueden ser imitados, aunque se asocien a un punto particular de origen, firma, región, sector o país (Scott 2006, 72).

La producción de los bienes y servicios culturales requieren creatividad humana; son trasmisores de mensajes simbólicos para quienes los consumen; contienen algún tipo de propiedad intelectual atribuible al individuo o al grupo que los crea (Throsby 2008a, 219). "Con el fin de ofrecer valor al consumidor, los productos culturales combinan elementos de estética, diseño y contenido narrativo, a menudo en mezclas complejas, tienen un valor de mercado limitado y, finalmente, necesitan ser reemplazados" (Lorenzen y Frederiksen 2008, 6). 


\section{Clasificación}

Resulta complejo valorar con precisión una clasificación que no genere ambigüedad al momento de conceptualizar las industrias culturales. Metodológicamente, la sistematización propuesta contempla sólo actividades secundarias y terciarias. La economía cultural se distingue por una agregación de sectores de productos no estandarizados en tecnología, negocios, servicios financieros, personales e industrias culturales, que van desde medios de comunicación hasta la artesanía de producción intensiva, que demandan estructuras de mano de obra y formas flexibles de elaboración (Scott 2014, 569).

Los servicios facilitan un esquema efectivo para explicar las interdependencias no comerciales, el contacto cara a cara, la movilidad laboral en mercados imperfectos y la fragmentación de uno especializado de firmas interrelacionadas. La base de datos se apoya en el SCIAN, cuyo antecedente se remonta a 1994, cuando Canadá, Estados Unidos y México desarrollaron un clasificador de actividades utilizado en la generación de la estadística económica, para solucionar las demandas de información derivadas del Tratado de Libre Comercio de América del Norte.

El SCIAN muestra cinco niveles de agregación, cada categoría de actividad tiene un código numérico. El número de dígitos varía según el nivel: sector (2), subsector (3), rama (4), subrama (5) y clase de actividad económica (6). No existe una publicación trinacional; cada país tiene una versión propia. El sector es el nivel más general y la clase el más desagregado. Cada subsector está formado por ramas de actividad, las cuales se dividen en subramas. Las clases, por su parte, son desgloses de las subramas (INEGI 2013, 17).

Para efectos de diseño del instrumento se retoma el ordenamiento sectorial del SCIAN, pero se excluyen algunos sectores, que para la clasificación de industrias culturales no son significativos en la cadena creativa de valor (creación, producción, distribución), éstos se relacionan con la distribución de bienes, y son: comercio al por mayor (43); comercio al por menor (46); trasportes, correo y almacenamiento (48-49); servicios financieros y de seguros (52); servicios inmobiliarios y de alquiler de bienes muebles e intangibles (53); corporativos (55); servicios de apoyo a los negocios y manejo de dese- 
chos y servicios de remediación (56); servicios de salud y asistencia social (62); otros servicios, excepto actividades gubernamentales (81) y los vinculados a estas últimas, que incluyen las legislativas, las gubernamentales, las de impartición de justicia y de los organismos internacionales y extraterritoriales (93). También se eliminaron subramas del sector (54) referentes a servicios legales (5411) y servicios de contabilidad, auditoría y otros relacionados (5412). Se incluyen sectores de actividades secundarias, vinculados a la trasformación de bienes, como el sector de las industrias manufactureras (31-33) y sus subsectores $(315,316,321,327,337)$, en algunas subramas específicas (véase Figura 3).

Figura 3. Ordenamiento de los sectores del SCIAN México, para una clasificación de industrias culturales/creativas en Culiacán, respecto a los sectores secundario y terciario, 2013

\begin{tabular}{|c|c|c|c|}
\hline $\begin{array}{l}\text { Agrupación } \\
\text { tradicional }\end{array}$ & $\begin{array}{c}\text { Característica general } \\
\text { de los sectores }\end{array}$ & & Sector \\
\hline $\begin{array}{l}\text { Actividades } \\
\text { secundarias }\end{array}$ & $\begin{array}{c}\text { Trasformación } \\
\text { de bienes }\end{array}$ & $31-33$ & Industrias manufactureras \\
\hline \multirow{3}{*}{$\begin{array}{c}\text { Actividades } \\
\text { terciarias }\end{array}$} & $\begin{array}{c}\text { Operaciones } \\
\text { con información }\end{array}$ & 51 & $\begin{array}{c}\text { Información } \\
\text { en medios masivos }\end{array}$ \\
\hline & $\begin{array}{c}\text { Servicios cuyo } \\
\text { insumo principal } \\
\text { es el conocimiento } \\
\text { y la experiencia } \\
\text { del personal }\end{array}$ & $\begin{array}{l}54 \\
61\end{array}$ & $\begin{array}{l}\text { Servicios profesionales, } \\
\text { científicos y técnicos, } \\
\text { servicios educativos }\end{array}$ \\
\hline & $\begin{array}{c}\text { Servicios } \\
\text { relacionados } \\
\text { con la recreación }\end{array}$ & $\begin{array}{l}71 \\
72\end{array}$ & $\begin{array}{l}\text { Servicios de esparcimiento, } \\
\text { culturales y deportivos, } \\
\text { y otros servicios recreativos. } \\
\text { Servicios de alojamiento } \\
\text { temporal y de preparación } \\
\text { de alimentos y bebidas }\end{array}$ \\
\hline
\end{tabular}

Fuente: elaboración propia, a partir de síntesis metodológica del SCIAN (INEGI 2013).

El SCIAN está integrado por 20 sectores de actividad; 5 son productores de bienes y 15 de servicios, aunque la distinción entre éstos no se refleja en la estructura. La Figura 4 contiene la desagregación en sectores de servicios y subsectores del ramo secundario. 
Figura 4. Estructura del SCIAN México:

categorías selectas, sectores secundario y terciario, 2013

\begin{tabular}{|c|c|c|c|c|c|c|}
\hline Código & Sector (títulos) & Sector & $\begin{array}{c}\text { Sub } \\
\text { sector }\end{array}$ & Rama & $\begin{array}{c}\text { Sub } \\
\text { rama }\end{array}$ & $\begin{array}{c}\text { Clase de } \\
\text { actividad }\end{array}$ \\
\hline $31-33$ & Industrias manufactureras & 1 & 5 & 19 & 42 & 90 \\
\hline 51 & Información y medios masivos & 1 & 6 & 12 & 27 & 35 \\
\hline 54 & $\begin{array}{c}\text { Servicios profesionales, } \\
\text { científicos y técnicos }\end{array}$ & 1 & 1 & 9 & 35 & 41 \\
\hline 61 & Servicios educativos & 1 & 1 & 7 & 19 & 38 \\
\hline 71 & $\begin{array}{c}\text { Servicios de esparcimiento, } \\
\text { culturales y deportivos y } \\
\text { otros servicios recreativos }\end{array}$ & 1 & 3 & 9 & 23 & 41 \\
\hline 72 & $\begin{array}{c}\text { Servicios de alojamiento } \\
\text { temporal y de preparación } \\
\text { de alimentos y bebidas }\end{array}$ & 1 & 2 & 6 & 10 & 22 \\
\hline
\end{tabular}

Fuente: elaboración propia, a partir del SCIAN (INEGI 2013).

Para optimizar el esfuerzo se acude a la categorización, a partir de dominios culturales (central, auxiliares y trasversales), que corresponde a la CGCFCS: "Un dominio es una categoría conceptual que puede reflejar una industria o grupo de establecimientos (por ejemplo, las industrias de cine), pero también puede describir un grupo de ocupaciones (por ejemplo, los trabajadores del filme), o una clase de productos (por ejemplo, las obras publicadas)" (Canadian Framework for Culture Statistics 2011, 36). Para clasificar industrias culturales dentro de grupos reconocibles, se pueden utilizar sujetos de mediciones para fines estadísticos. El resultado es un orden sucinto de industrias culturales flexibles en Culiacán (véase Figura 5).

Figura 5. Clasificación de industrias culturales/creativas en Culiacán

\begin{tabular}{|c|c|}
\hline Artes escénicas en vivo & Grabación de sonido \\
\hline Patrimonio y bibliotecas & Diseño \\
\hline Artes visuales y aplicadas & Arquitectura \\
\hline Publicación y redacción & Publicidad \\
\hline Medios audiovisuales interactivos & \\
\hline
\end{tabular}

Fuente: elaboración propia, a partir de la CGCFCS (Canadian Framework for Culture Statistics 2011). 


\section{Resultados y discusión del ordenamiento de industrias culturales/creativas}

\section{a partir de una metodología de clasificación para Culiacán}

En este apartado se presenta un ejercicio de categorización de establecimientos inscritos en el Directorio estadístico nacional de unidades económicas, DENUE (2014). Se elabora un concentrado de unidades económicas de los servicios, por sector, subsector y rama, y se detalla la propuesta para clasificación (véase Figura 6).

El ordenamiento a partir de la clasificación explica la operatividad de industrias culturales en una ciudad media, a través de la integración por grupos de industrias basadas en la similitud de la estructura de productos, mano de obra y procesos de producción. Así, en la categorización por establecimientos (véase Figura 6), la industria de la publicación y redacción concentra a 12 empresas dedicadas a la edición de periódicos, revistas, libros y similares y a la impresión, con 60 empleados; más de la mitad de estos negocios del subsector se aglomera en la ciudad.

Los medios audiovisuales interactivos están constituidos por unidades del sector información en medios masivos, relacionadas con la edición de software y también del software integrado con la reproducción, la industria fílmica y del video, la trasmisión de programas de radio y televisión, la producción de programas para canales de sistemas de televisión por cable o satelitales, los operadores de telecomunicaciones inalámbricas, concentradas en 116 establecimientos, con 580 empleados. En el mismo sector se encuentra la industria de la grabación del sonido, con siete unidades representativas y 35 empleados. La aproximación respecto al personal ocupado parte de que son cinco empleados en promedio, por establecimiento (véase Figura 1), y se infiere que éstos son pequeños.

En el cotejo estadístico, los servicios profesionales, científicos y técnicos (54) incluyen industrias culturales del diseño, arquitectura y publicidad. El ordenamiento y la arquitectura están constituidos por 66 empresas en ramas de servicios de arquitectura, de paisaje y urbanismo, de ingeniería, dibujo, inspección de edificios, geofísica, elaboración de mapas y pruebas. El subsector de los servicios de arquitectu- 


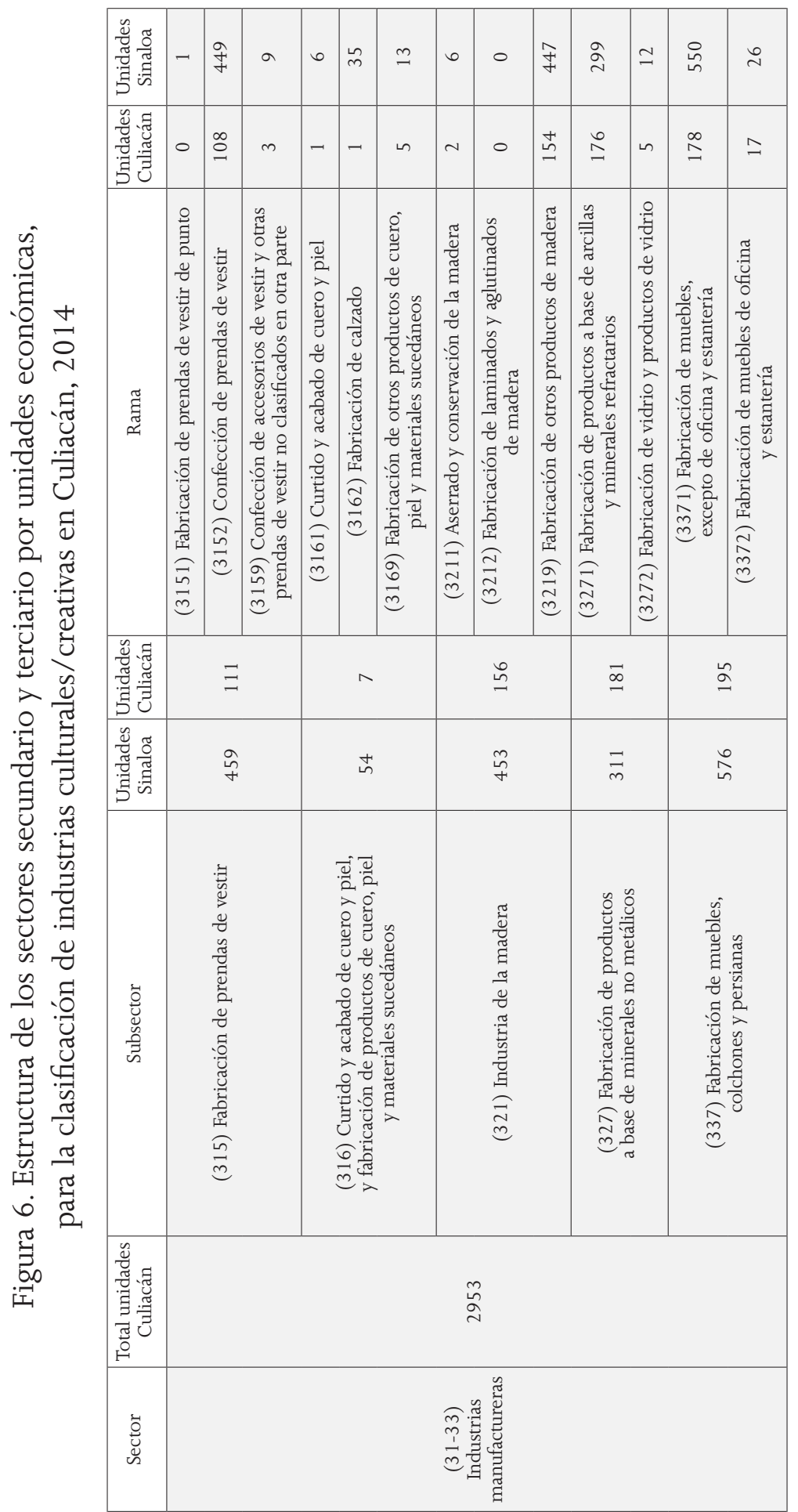




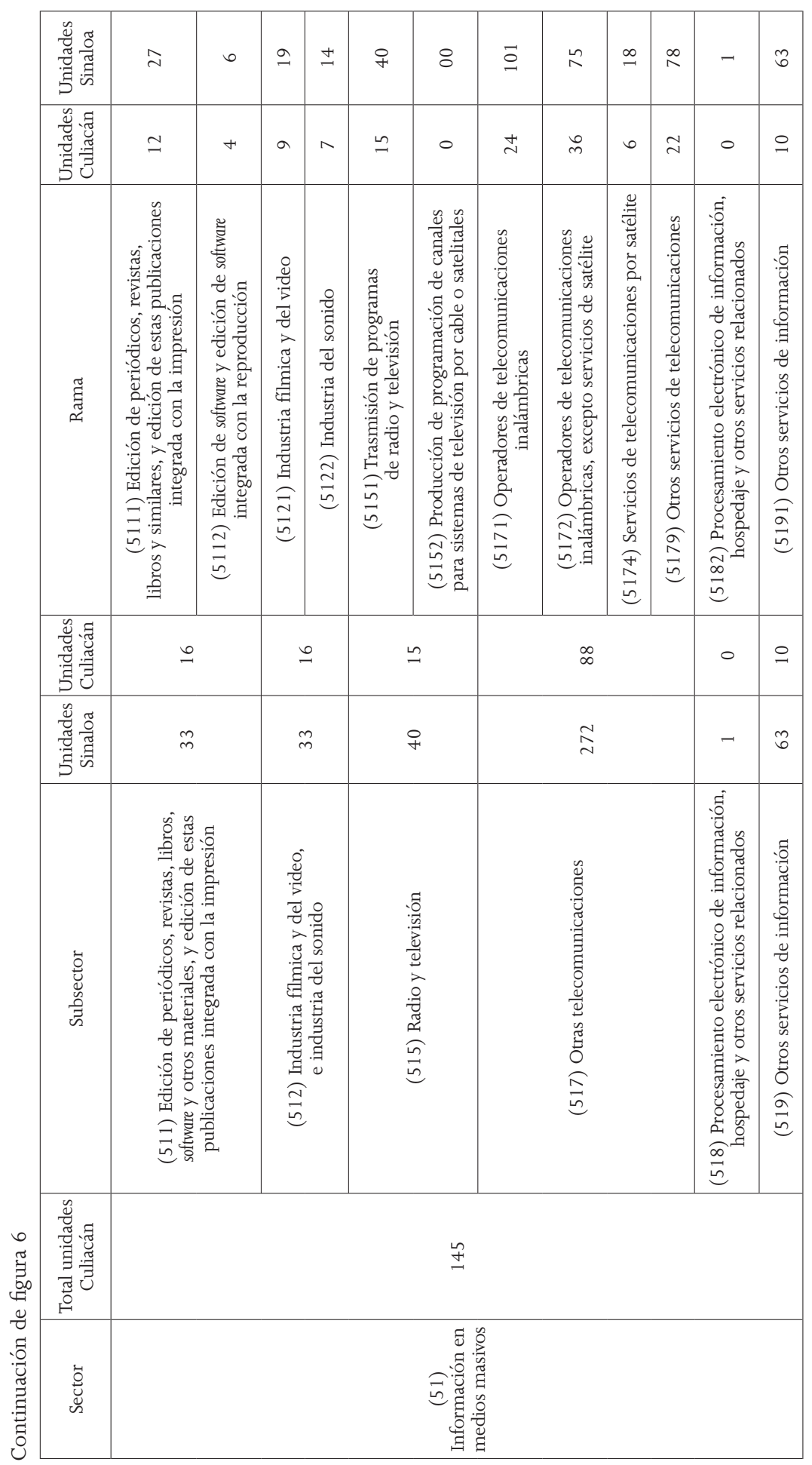




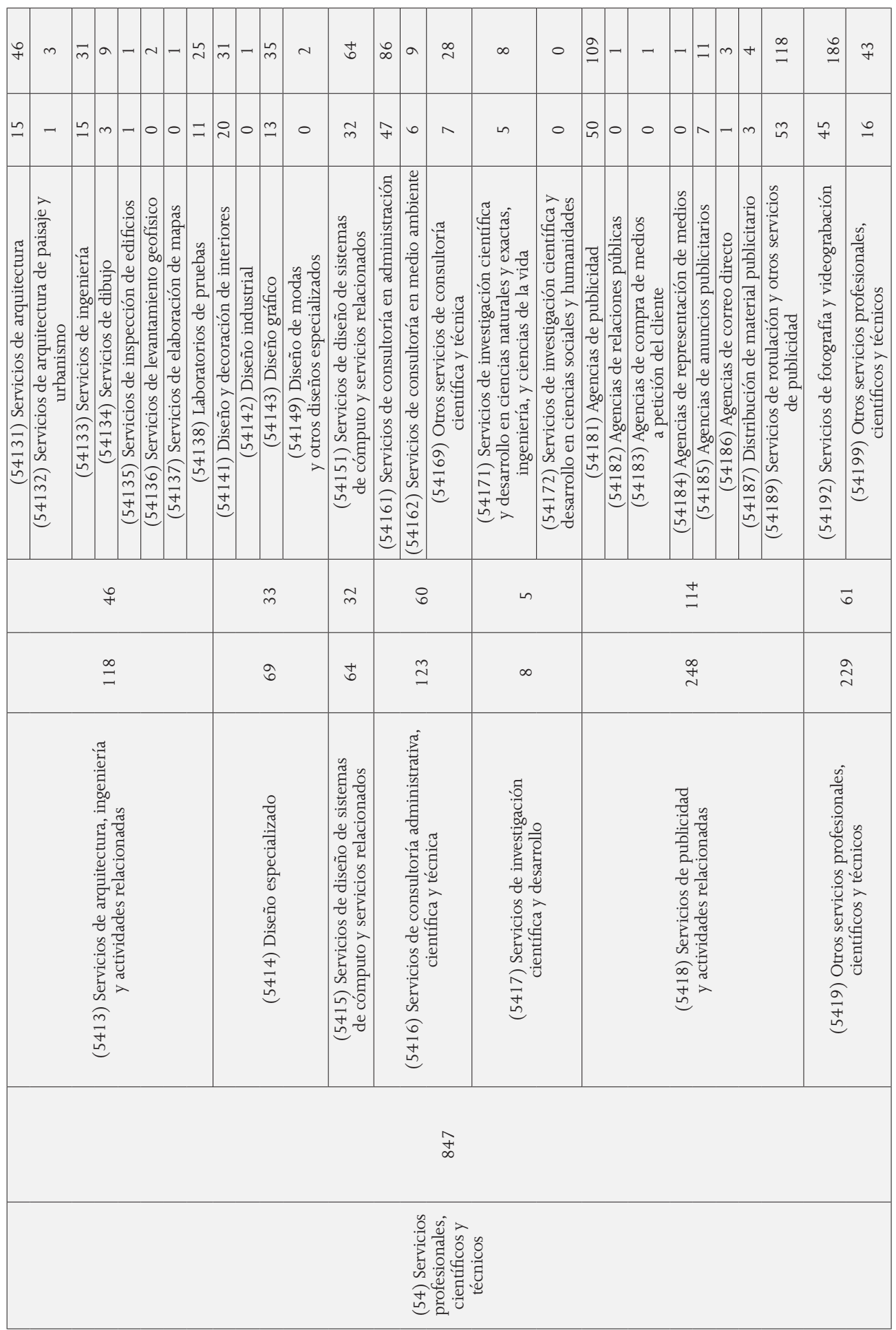




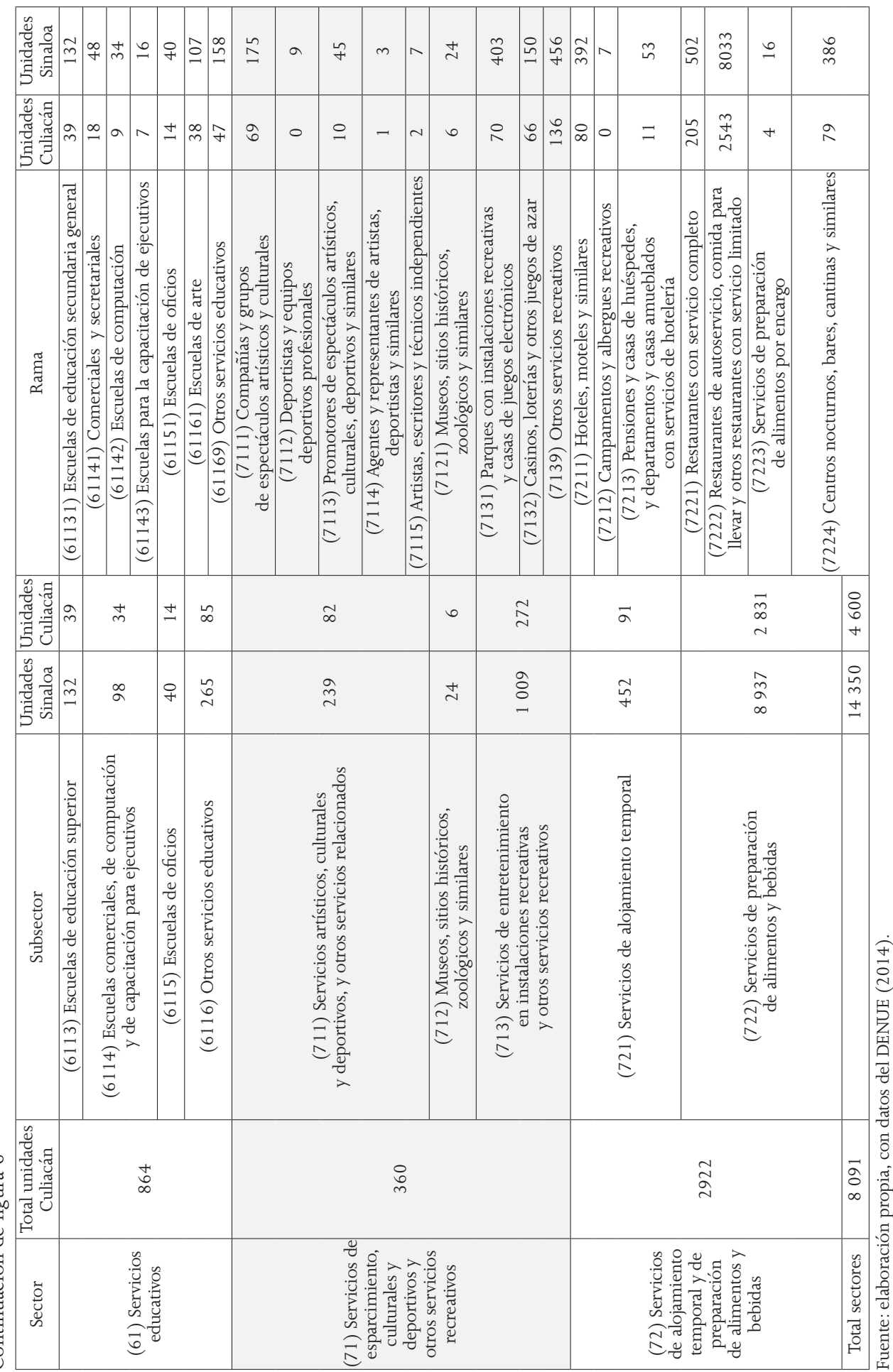


ra representa 55.9 por cierto de los 118 establecimientos vinculados en el total estatal, y posiciona en la ciudad al mayor agrupamiento de servicios, cuya mano de obra se estima en 330 empleados.

En cuanto al diseño, en el centro de la ciudad se ubican 65 empresas, relativas a la decoración de interiores y al diseño en varias ramas, como el industrial, el gráfico, de modas y otros especializados, también servicios de diseño de sistemas de cómputo y otros relacionados. Respecto al subsector estatal del diseño especializado (133 establecimientos) significan 48.8 por ciento, por ello incuban un nicho proliferante de insumo creativo y actividad intelectual, con bienes y servicios de valor simbólico y distinción personal.

La publicidad es la más representativa del sector de los servicios profesionales, con 114 establecimientos y alrededor de 570 empleados, cuyas ocupaciones son especializadas en agencias de publicidad, de relaciones públicas, compra de medios a petición del cliente, representación de medios, de anuncios publicitarios, correo directo, material publicitario y servicios de rotulación y de publicidad. El total de negocios aglomerados constituye 45.9 por ciento de las 248 empresas de publicidad ubicadas en el estado.

También es posible clasificar a la industria cultural de las artes escénicas en vivo, a partir del subsector servicios artísticos, culturales y deportivos y otros relacionados, que detenta 82 establecimientos y cerca de 410 empleados, con ocupaciones en 69 compañías y grupos de espectáculos artísticos y culturales y, en menor número, las empresas relacionadas con deportistas y equipos deportivos profesionales, promotores de espectáculos artísticos, culturales, deportivos y similares, agentes y representantes de artistas, deportistas y similares. La tendencia de las compañías artísticas de Sinaloa indica que 34.3 por ciento prefiere ubicarse en Culiacán.

La industria de patrimonio y bibliotecas cuenta con seis unidades entre museos, sitios históricos, zoológicos y similares, un estimado de 30 trabajadores, que equivalen a 25 por ciento del total en el estado.

Las artes visuales y aplicadas representan 34 por ciento del total estatal, con actividades vinculadas al arte visual original, artesanías y fotografía, identificadas por establecimientos del sector secundario, como la fabricación y confección de prendas de vestir, accesorios y 
calzado, el curtido, acabado y fabricación de productos de cuero y piel, de madera, a base de arcillas y minerales refractarios, de vidrio y de muebles; y del sector terciario, por 45 empresas de servicios de fotografía y videograbación. La estructura de empleo en las artes visuales se puede aproximar a cinco empleados por unidad, en promedio, a 3475 si se contemplan 695 unidades, de las cuales las más numerosas se relacionan con la fabricación de muebles, productos de madera y a base de arcillas y minerales refractarios.

En el ordenamiento se incluyen los servicios de entretenimiento en instalaciones recreativas y otros (272 unidades); de alojamiento temporal (91) y de preparación de alimentos y bebidas (2 832); de consultoría administrativa, científica y técnica (60); de investigación científica y desarrollo (5) y otros servicios profesionales, científicos y técnicos (16) y los educativos (864), que si bien no se consideran dominios culturales centrales, sus ocupaciones posibilitan la operatividad de la cadena cultural creativa y, para efectos de este análisis, corresponden a subdominios culturales auxiliares, cuyo propósito central no es la trasmisión de un concepto intelectual o cultural, sus productos tienen un fin práctico; a dominios trasversales, que consisten en actividades, productos y ocupaciones intersectoriales que apoyan a la cultura y posibilitan el funcionamiento de la cadena cultural creativa (Canadian Framework for Culture Statistics 2011, 14-95); o a dominios de infraestructura (espacios construidos que albergan actividades relacionadas con industrias culturales).

Ejemplo de esto es el sector educativo, que apoya la dinámica de las industrias culturales con la capacitación, la generación de conocimiento, el aprendizaje intensivo y las habilidades necesarias para asegurar el suministro de mano de obra especializada en el sistema de producción. También están los servicios de alojamiento temporal y de preparación de alimentos y bebidas, que participan de manera directa en el turismo y la gastronomía -dominios trasversales, auxiliares y de infraestructura- determinantes para las nueve industrias culturales centrales clasificadas aquí que, en general, para el ordenamiento representan 32 por ciento respecto al total estatal. Esta tendencia hacia la centralidad de la ciudad es característica de los procesos espaciales de las industrias culturales, cuyo sistema de producción confía en las especificidades del espacio urbano y su entramado de interacciones sociales. 


\section{Conclusiones}

La economía cultural no es, en absoluto, un discurso reciente en el análisis económico, más sí la fragmentación en las formas de producción, consumo y distribución, que centran el valor de la cultura y la creatividad como insumos del sistema capitalista. Al incorporar productos adaptables a las formas más ambiguas de comercialización, que responden a una demanda especializada creciente, la cultura consolida su presencia en la economía. Es así que los bienes y servicios son manifiestos en industrias culturales de alto contenido creativo, constituidas por sectores con preferencia por los procesos intelectuales, ideas, trasmisión de conocimientos e innovación orientados a satisfacer la demanda de mercancías simbólicas de contenido, en ocasiones, intangible.

La expresión moderna de estas industrias las va posicionando como herramientas de regeneración y desarrollo económico, con gravámenes positivos sobre las economías. No obstante, en la literatura existe un cisma conceptual que confronta la antigua discusión economía-industria-cultura, con las terminologías y derivaciones que dificultan el establecimiento de su estructura y límites de operación.

En este razonamiento, la contribución de las industrias culturales a la dinámica productiva de países, regiones y localidades es poco clara, pues carecen de sistemas de clasificación, herramientas de medición y bases de datos comparables e intercambiables, que faciliten estimar su aportación a la economía. Este problema es aún más evidente a escala municipal, pues las grandes regiones y las metrópolis concentran la atención del fenómeno, al suponer que es nulo en localidades medianas o chicas. No obstante, el incremento en la red de concentraciones dedicadas a la producción de bienes y servicios culturales provoca una pugna general por acelerar las ventajas competitivas en todos los ámbitos territoriales, entonces ¿cómo determinar su contribución a la estructura económica de un lugar? En este análisis, la respuesta condujo a esquematizar una propuesta metodológica para clasificar las industrias culturales en una ciudad media.

El esfuerzo metodológico concreta un ordenamiento que precisa la operatividad de industrias culturales, sus características y variedad. Este esquema facilita el cotejo estadístico de ramas económicas de los 
sectores secundario y terciario de la ciudad, y descarta actividades no compatibles con la conceptualización de industrias culturales.

A partir de la clasificación, el ordenamiento arma la estructura de firmas, estima el número de empleados y cuantifica la participación en el crecimiento de nueve industrias culturales: artes escénicas en vivo, grabación de sonido, patrimonio y bibliotecas, diseño, artes visuales y aplicadas, arquitectura, publicación y redacción, publicidad y medios audiovisuales interactivos, que conforman una agrupación de unidades económicas en el centro de la ciudad. Asimismo, es posible distinguir ocupaciones creativas dedicadas a nichos de producción estratificados en bienes y servicios personalizados, de alta tecnología y contenido creativo, simbólicos, efímeros para el consumo y con elasticidad ingreso positivo.

La delimitación de estas industrias indica un crecimiento en el volumen de mano de obra especializada, ocupaciones y empresas creativas en Culiacán, en el periodo de referencia; se trata de una concentración comercial en el centro, con actividades funcionales en el espacio geográfico común conectadas al resto de la ciudad. Se debe reconocer que la asociación de categorías y conceptos propuestos en este análisis puede provocar dispersión, omisión en la recolección de datos y, en general, procesos parciales. La detección de un sistema articulado para la producción cultural en Culiacán no condiciona que las industrias clasificadas convengan a los esquemas desarrollados en otros lugares, y tampoco unilateralismo en la metodología implementada, pero sí determinar que en ciudades medias es posible encontrar actividades motrices que sugieren rasgos de la economía cultural moderna.

\section{Bibliografía}

Adorno, Theodore W. 1991. The culture industry, selected essays on mass culture. Londres: Routledge.

Amin, Ash y Nigel Thrift. 2007. Cultural-economy and cities. Progress in Human Geography 31 (2): 143-161. 
Canadian Framework for Culture Statistics. 2011. Classification guide for the Canadian framework for culture statistics 2011. Ottawa, Canadá.

Consejo Nacional de Población. 2012. Catálogo. Sistema Urbano Nacional 2012. http://www.conapo.gob.mx/work/models/ CONAPO/Resource/1539/1/images/PartesIaV.pdf (12 de mayo de 2016).

DENUE. 2014. http://www3.inegi.org.mx/sistemas/mapa/denue/ Cuantificar.aspx (10 de noviembre de 2014). / http://www.beta. inegi.org.mx/app/mapa/denue/

Evans, Graeme. 2009. Creative cities, creative spaces and urban policy. Urban Studies 46 (5-6): 1003-1040.

Flew, Terry. 2002. Beyond ad hocery: defining creative industries. Artículo presentado en Cultural Sites, Cultural Theory, Cultural Policy, The Second International Conference on Cultural Policy Research, (1-30). Te Papa, Wellington, Nueva Zelanda.

Florida, Richard. 2003. Cities and the creative class. City \& Community 2:3-19.

Galloway, Susan y Stewart Dunlop. 2007. A critique of definitions of the cultural and creative industries in public policy. International Journal of Cultural Policy 13 (1). DOI: 10.1080/10286630701201657

Guerrero, P. Gerardo y Clemente Navarro. 2012. Industrias culturales en ciudades españolas. Un primer acercamiento. Revista de Estudios Regionales 7585 (94): 71-103.

Hesmondhalgh, David. 2007. The cultural industries. Learning 11 (3): 356-361.

Hesmondhalgh, David. 2002. The cultural industries. Londres: Sage Publications. 
Hutton, A. Thomas. 2006. Spatiality, built form, and creative industry development in the inner city. Environment and Planning A 38(10): 1819-1841.

INEGI. 2016. Información por entidad, Sinaloa. http://cuentame. inegi.org.mx/monografias/informacion/Sin/Poblacion/default. aspx?tema $=$ ME\&e $=25$ (12 de mayo de 2017).

INEGI. 2014a. Banco de información. http://www3.inegi.org.mx/ sistemas/biinegi/ (22 de octubre de 2014).

INEGI. 2014b. Sistema de Cuentas Nacionales de México. Producto interno bruto por entidad federativa, 2005-2009. http://cuentame.inegi.org.mx/monografias/informacion/sin/economia/default.aspx?tema $=$ me\&e $=25$ (10 de noviembre de 2014).

INEGI. 2013. Sistema de Clasificación Industrial de América del Norte (SCIAN) http://www.inegi.org.mx/est/contenidos/proyectos/ SCIAN/presentacion.aspx?div=C2 (17 de octubre de 2015).

Kong, Lily. 2014. From cultural industries to creative industries and back ? Towards clarifying theory and rethinking policy. Inter-Asia Cultural Studies 15 (4): 593-607.

Landry, Charles y Franccesco Bianchini. 1995. The creative city. Reino Unido: Demos.

Lazzeretti, Luciana. 2009. The creative capacity of culture and the new creative milieu. En $A$ handbook of industrial districts, compilado por Giacomo Becattini, Marco Bellandi y Lisa De Propris, 281-294. Cheltenham, Reino Unido: Edward Elgar.

Lazzeretti, Luciana, Francesco Capone y Seçilmi, I. Erdem. 2015. In search of a Mediterranean creativity. Cultural and creative industries in Italy, Spain and Turkey. European Planning Studies 24 (3): 568588. 
Lazzeretti, Luciana, Rafael Boix y Francisco Capone. 2009. Why do creative industries cluster? An analysis of the determinants of clustering of creative industries. IERMB Working paper in economics.

Lazzeretti, Luciana, Rafael Boix y Francesco Capone. 2008. Do creative industries cluster? Mapping creative local production systems in Italy and Spain. Industry and Innovation 15 (5): 549-567.

Lorenzen, Mark y Lars Frederiksen. 2008. Why do cultural industries cluster? Localization, urbanization, products and projects. En Creative cities, cultural clusters and local economic development, editado por Luciana Lazzaretti y Philip Cooke, 155-179. Cheltenham: Edward Elgar Publishing.

Lorenzini, Eleonora. 2011. The Extra-urban cultural district: an emerging local production dystem: three Italian vase dtudies. European Planning Studies 19 (8):1441-1457.

Markusen, Ann y Greg Schrock. 2006. The artistic dividend: urban artistic specialisation and economic development implications. Urban Studies 43 (10): 1661-1686.

Markusen, Ann, Gregory H. Wassall, Douglas Denatale y Randy Cohen. 2008. Defining the creative economy: industry and occupational approaches. Economic Development Quarterly 22 (1): 24-45.

Mckenzie, Murray y Thomas A. Hutton. 2015. Culture-led regeneration in the post-industrial built environment: complements and contradictions in Victory Square, Vancouver. Journal of Urban Design 20 (1): 8-27.

Mokyr, Joel. 2017. A Culture of growth:the origins of the modern economy. Princeton: Princeton University Press.

Mommaas, Hans. 2009. Spaces of culture and economy: mapping the cultural-creative cluster landscape. En Creative economies, creative 
cities: Asian-European Perspectives, compilado por Lily Kong y Justin O’Connor, 45-59. Dordrecht: Springer.

Mommaas, Hans. 2004. Cultural clusters and the post-industrial city: towards the remapping of urban cultural policy. Urban Studies 41 (3): 507-532.

Montgomery, John. 2003. Cultural quarters as mechanisms for urban regeneration. Part 1: conceptualising cultural quarters. Planning Practice and Research 18 (4): 293-306.

O'Connor, Justin. 2011. Las industrias creativas y culturales: una historia crítica. Ekonomiaz 3 (78): 25-47.

O'Connor, Justin. 2007. The cultural and creative industries: a review of the literature, a report for creative partnerships. Londres: Creative Partnerships and Arts Council England.

O'Connor, Justin. 2000. The definition of the "cultural industries." The European Journal of Arts Education 2 (3): 15-27.

Peltoniemi, Mirva. 2015. Cultural industries: product-market characteristics, management challenges and industry dynamics. International Journal of Management Reviews 17 (1): 41-68.

Pratt, C. Andy. 2008. Creative cities: the cultural industries and the creative class. Geografiska Annaler, Series B: Human Geography 90 (2): 107 117.

Pratt, C. Andy. 2004. Mapping the cultural industries: regionalization; the example of south-east England. En Cultural industries and the production of culture, de A. J. Scott y D. Power, 19-36. Londres: Routledge.

Pratt, C. Andy. 1997. The cultural industries sector: its definition and character from secondary sources on employment and trade, Britain 1984-91. Research Papers in Environmental and Spatial Analysis (41): $1-50$. 
Scott, J. Allen. 2014. Beyond the creative city: cognitive-cultural capitalism and the new urbanism. Regional Studies 0 (4): 1-14.

Scott, J. Allen. 2010. Cultural economy and the creative field of the city. Geografiska Annaler: Series B, Human Geography 92 (2): 115-130.

Scott, J. Allen. 2008. Social economy of the metropolis, cognitive-cultural capitalism and the global resurgence of cities. Nueva York: Oxford University Press.

Scott, J. Allen. 2006. Geography and economy. Oxford, Nueva York: Oxford University Press.

Scott, J. Allen. 2001. Capitalism, cities, and the production of symbolic forms. Royal Geographical Society 26 (13):11-23.

Scott, J. Allen. 1997. The cultural economy of cities. International Journal of Urban and Regional Research 21 (2): 323-339.

Stevens, Quentin. 2015. Creative milieux: how urban design nurtures creative clusters. Journal of Urban Design 20 (1): 1-7.

Throsby, David. 2008a. Modelling the cultural industries. International Journal of Cultural Policy 14 (3): 217-232.

Throsby, David. 2008b. The concentric circles model of the cultural industries. Cultural Trends 17 (3): 147-164.

Throsby, David. 2001. Economics and culture. Cambridge: Cambridge University Press.

United Nation Conference on Trade and Development. 2013. Trade in creative products reached new peak in 2011, UNCTAD figures show. wwww.unctad.org (11 de diciembre de 2015).

United Nations Development Programme y United Nations Educational y Science and Culture Organization. 2013. Creative Economy Report 2013, special edition. Widening local development 
pathways. http://www.unesco.org/culture/pdf/creative-economy-report-2013.pdf (11 de noviembre de 2014).

Van Heur, Bas. 2009. The clustering of creative networks: between myth and reality. Urban Studies 46 (April 2008): 1531-1552.

Zukin, S. 1995. The cultures of cities. Massachusetts: Blackwell Publishing Inc. 